\title{
Penerapan Model Pembelajaran Quantum Teaching berbantuan Media Konkret untuk Meningkatkan Hasil Belajar IPA
}

\author{
Luh Putu Purnama Dewi
}

SMP Negeri 2 Kubu, Karangasem, Indonesia

A R T I C L E I N F O

Article history:

Received 19

November 2018

Received in revised form

6 Januari 2018

Accepted 12 Januari 2018

Available online 20

Februari 2018

Kata Kunci:

Model Pembelajaran,

Quantum Teaching,

Hasil Belajar.

Keywords:

Learning Model,

Quantum Teaching,

Learning Outcomes.

\section{A B S T R A K}

Penelitian ini bertujuan untuk mengetahui hasil belajar IPA siswa kelas IXB semester ganjil SMP Negeri 2 Kubu setelah diterapkannya model pembelajaran quantum teaching berbantuan media konkret. Subjek penelitian ini adalah seluruh siswa kelas IXB SMP Negeri 2 Kubu yang terdiri dari 40 orang siswa, 22 siswa laki-laki dan 18 orang siswa perempuan. Penelitian ini merupakan Penelitian Tindakan Kelas yang dilaksanakan dalam dua siklus. Setiap Siklus terdiri dari 3 kali pertemuan yang di dalamnya terdiri atas perencanaan, tindakan, pemantauan, serta refleksi. Data hasil belajar siswa dikumpulkan melalui tes tulis pada setiap akhir siklus. Data yang telah dikumpulkan tersebut dianalisis dengan menggunakan analisis kuantitatif. Hasil penelitian ini menunjukkan bahwa penerapan model pembelajaran quantum teaching dapat meningkatkan hasil belajar siswa. Hal ini ditunjukkan dari nilai rata-rata hasil tes siklus I sebesar 66,8 dengan tingkat ketuntasan belajar $50 \%$ dan nilai rata-rata siklus II sebesar 81,6 dengan tingkat ketuntasan belajar $87,5 \%$

\section{A B S T R A C T}

This study was aimed finding out the science learning achievement of the students of class IXB in the odd smester at SMP Negeri 2 Kubu after concrete media-aided quantum teaching model was applied. The subjects consisted of all of the 40 students of class IXB SMP Negeri 2 Kubu, 22 males and 18 females. This study was a class action research which was conducted in 2 cycles. Every cycle consisted of three meetings, each of them consisted of planning, action, observation, and reflection. The data on the students' learning achievement were collected through a written test at the end of every cycle. The data collected were analyzed using quantitative analysis. The result showed that the implementation of quantum teaching model can increase the students' learning achievement. This was shown by the mean scores in the first cycle (66.8 with 50\% learning completeness level and the average score in the second cycle (81.6 with $875 \%$ learning completeness level. 


\section{Pendahuluan}

Pendidikan merupakan pondasi utama dalam mengelola, mencetak, dan meningkatkan SDM yang berkualitas tinggi. Pendidikan dapat mengembangkan berbagai potensi yang dimiliki manusia secara optimal, yaitu mengembangkan potensi individu yang setinggi-tingginya dalam aspek fisik, intelektual, emosional sosial dan spiritual, untuk itu pemerintah selalu berupaya untuk meningkatkan mutu pendidikan baik pada jenjang pendidikan dasar, menengah maupun jenjang pendidikan tinggi guna mempersiapkan sumber daya manusia yang berkualitas. Pendidikan adalah upaya untuk memanusiakan manusia atau membentuk manusia menjadi manusia seutuhnya. Dikatakan demikian karena dengan pendidikan manusia dapat dibentuk untuk lebih sempurna dari mahluk Tuhan yang lainnya sebagai kalifah di muka bumi (Susiani, 2013). Hal ini terkandung dalam tujuan pendidikan nasional, bahwa pendidikan nasional bertujuan untuk mencerdaskan kehidupan bangsa dan mengembangkan manusia seutuhnya, beriman, bertakwa kepada Tuhan Yang Maha Esa serta sehat jasmani dan rohani juga memiliki kemampuan dan keterampilan. Pengembangan IPTEK berkaitan erat dengan penguasaan IPA (Juniati, 2017).

IPA merupakan suatu ilmu yang bersifat objektif yang mempelajari tentang alam sekitar beserta isinya, peristiwa dan gejala-gejala yang muncul di alam berdasarkan fakta, konsep, prinsip dan hukum yang teruji kebenarannya dan melalui suatu rangkaian dalam metode ilmiah (Nuryati, 2015). Pendidikan IPA Terpadu merupakan produk Kurikulum Tingkat Satuan Pendidikan (KTSP) 2006 dalam rangka melaksanakan amanat Undang-undang Nomor 23 Tahun 2003 tentang Sistem Pendidikan Nasional (Sisdiknas). IPA terpadu hanya dikhususkan untuk siswa jenjang Sekolah Dasar (SD) dan Sekolah Menengah Pertama (SMP). Pendidikan IPA Terpadu (integrated science) mencoba menggabungkan, memadukan dan mengintegrasikan pembelajaran IPA dalam satu kesatuan yang utuh. Dengan pengimplementasian pembelajaran IPA Terpadu ini, diharapkan materi-materi IPA yang terpisah-pisah dalam beberapa bidang studi, yakni Fisika, Kimia, dan Biologi dapat diajarkan secara terpadu dan menyeluruh dalam satu bidang studi, IPA Terpadu. Faktor-faktor penentu dalam meningkatkan hasil belajar peserta didik di sekoah seperti umpan balik, model pembelajaran, motivasi diri, gaya belajar, interaksi, dan instruktur fasilitasi sebagai penentu potensi keberhasilan pembelajaran (Yanuarti, 2016). Dalam pencapaian kompetensi yang ditetapkan, banyak hal juga yang harus dilakukan oleh guru, seperti menentukan metode, model, media, strategi, serta keterampilan mengajar yang mampu memotivasi siswa agar lebih semangat dalam aktivitas pembelajaran. Ini dimaksudkan agar konsep atau materi menjadi lebih bermakna bagi siswa, apalagi jika penemuan konsep dilakukan oleh siswa secara individu maupun bekerja sama dengan teman dalam kelompok. Untuk memudahkan siswa dalam menemukan konsep, maka dari itu guru dituntut kekreatifanya dalam memberikan bimbingan terhadap siswanya, serta bagaimana guru dapat menyampaikan informasi tersebut agar bermakana bagi siswa (Syukur, 2014). Selain guru siswa juga harus memiliki kemampuan koneksi penting dimiliki oleh siswa agar mereka mampu menghubungkan antara materi yang satu dengan materi yang lainnya (Linto, 2012).

Hasil belajar merupakan pencapaian tujuan pendidikan pada peserta didik yang mengikuti proses belajar mengajar. Hasil belajar merupakan realisasi tercapainya tujuan pendidikan, sehingga hasil belajar yang diukur sangat tergantung kepada tujuan pendidikannya (Muslikhah, 2016). Pemerintah melalui Kementerian Pendidikan dan Kebudayaan terus berupaya memperbaiki kualitas pendidikan Indonesia dengan melakukan perbaikan kurikulum. Kurikulum yang baru saja diterapkan dengan tujuan untuk mempersiapkan manusia Indonesia agar memiliki kemampuan hidup sebagai pribadi dan warga negara yang beriman, produktif, kreatif, inovatif, dan afektif serta mampu berkontribusi pada kehidupan bermasyarakat, berbangsa, bernegara, dan peradaban dunia yaitu kurikulum 2013 (Permendikbud No.70 Tahun 2013).

Harapan di atas tidak sejalan dengan kenyataan yang terjadi di SMP Negeri 2 Kubu. Berdasarkan hasil pencatatan dokumen nilai IPA, hasil belajar IPA siswa kelas IXB SMP Negeri 2 Kubu masih jauh dari harapan. Hasil ulangan harian I menunjukkan ketuntasan belajar siswa hanya mencapai 37,5\% dengan nilai rata-rata kelas hanya mencapai 64,0. Nilai rata-rata kelas masih berada di bawah KKM yang ditetapkan sekolah yaitu 74. Rendahnya hasil belajar disebabkan karena pembelajaran yang dilakukan belum mencerminkan pembelajaran yang inovatif. Pembelajaran dilakukan dengan cara guru menyampaikan materi di depan kelas dan siswa memperhatikan penjelasan guru. Guru kurang memberikan contoh penerapan materi pembelajaran dalam kehidupan sehari-hari atau bahkan mendemonstrasikannya di depan kelas. Hal ini membuat siswa kurang antusias dalam pembelajaran sehingga hasil pembelajaran menjadi kurang maksimal.

Untuk mengatasi kesenjangan tersebut, peneliti ingin menerapkan model quantum teaching berbantuan media konkrit dalam pembelajaran IPA terpadu di kelas IXB SMP Negeri 2 Kubu. Model quantum teaching berupaya menumbuhkan minat belajar siswa dengan mengaitkan materi pelajaran 
(konten) dengan kehidupan sehari-hari (konteks). Quantum teaching merupakan salah satu cara dalam usaha mengembangkan kemampuan pemahaman konsep matematis siswa. Quantum teaching menekankan agar siswa mengetahui dan memahami bentuk nyata dari pembelajaran yang berlangsung dengan bantuan aktivitas yang diberikan guru (Murizal, 2012). Hal tersebut membuat siswa tidak mengkhayal dalam membayangkan suatu konsep materi yang dipelajari. Sehingga siswa mampu mengungkapkan konsep matematikanya dengan bahasa yang benar dan mudah dipahami. Adanya hal tersebut kemampuan pemahaman konsep matematis siswa dapat dikembangkan. Quantum teaching menginteraksi segala komponen di dalam kelas dan lingkungan sekolah untuk dirancang sedemikian rupa sehingga semua berbicara dan bertujuan untuk kepentingan siswa, sehingga siswa dapat mengembangkan diri dan pengetahuannya. Quantum Teaching adalah suatu metode pembelajaran yang menyenangkan dengan interaksi antara guru dan siswa yang terjalin dengan baik (DePorter, et al., 2011:44). Metode quantum teaching membantu dalam menciptakan lingkungan belajar yang efektif dengan cara memanfaatkan unsur-unsur yang ada pada siswa, misalnya rasa ingin tahu siswa dan lingkungan belajarnya melalui interaksi-interaksi yang terjadi di dalam kelas. DePorter, et al., (2011:39) mengatakan bahwa dalam pengimplementasian model quantum teaching menggunakan tahapan-tahapan pembelajaran dengan sebutan TANDUR (Tumbuhkan, Alami, Namai, Demonstrasi, Ulangi, dan Rayakan). Alasan penelitian ini menerapkan model quantum teaching adalah terciptanya pembelajaran yang menyenangkan untuk memancing keaktifan siswa dalam belajar sehingga siswa mendapatkan hasil belajar yang lebih maksimal. Penerapan model pembelajaran quantum teaching berbantuan media konkrit diharapkan mampu meningkatkan hasil belajar siswa kelas IXB SMP Negeri 2 Kubu semester ganjil tahun pelajaran 2016/2017. Berdasarkan latar belakang masalah tersebut, penelitian ini memusatkan perhatian untuk menjawab rumusan masalah sebagai berikut; "Apakah penerapan model pembelajaran quantum teaching berbantuan media konkrit dapat meningkatkan hasil belajar IPA siswa kelas IXB semester ganjil SMP Negeri 2 Kubu?"

\section{Metode}

Jenis penelitian yang dilaksanakan adalah penelitian tindakan kelas (classroom action research). Penelitian ini dilaksanakan di SMP Negeri 2 Kubu. Sekolah ini terletak di Desa Tianyar, Kecamatan Kubu, Kabupaten Karangasem. Kelas yang akan diteliti adalah kelas IXB tahun pelajaran 2016/2017 yang berjumlah 40 orang. Penelitian ini akan dilakukan pada semester ganjil bulan Agustus minggu ketiga sampai kelima. Objek penelitian yang di ambil dalam penelitian ini adalah hasil belajar IPA. Penelitian dilaksanakan pada minggu kedua bulan Agustus sampai minggu pertama bulan September.

Oleh karena penelitian ini merupakan Penelitian Tindakan Kelas (PTK), maka prosedur penelitian ini sesuai dengan prosedur penelitian tindakan kelas yang dilakukan dalam suatu proses berdaur/ bersiklus. Setiap siklus terdiri atas empat fase, yaitu: 1) Perencanaan (planning) ,2) tindakan (action), 3) Pemantauan (observation), 4) Refleksi (reflection). Namun, keputusan untuk melanjutkan atau menghentikan penelitian pada siklus tertentu bergantung sepenuhnya pada hasil yang dicapai pada siklus terakhir. Bila hasil yang dicapai telah memenuhi kriteria keberhasilan yang telah diterapkan, maka penelitian dihentikan. Bila hasil yang dicapai belum sesuai dengan yang diharapkan, maka penelitian dilanjutkan ke siklus berikutnya. Data hasil belajar siswa dikumpulkan dengan metode tes dengan kriteria penskoran yang telah ditetapkan peneliti. Skor yang diperoleh masing-masing siswa akan dihitung kembali menggunakan rumus tertentu untuk bisa dideskripsikan. Instrumen yang digunakan untuk mengumpulkan data ini adalah dengan menggunakan butir-butir soal yang relevan dengan pembelajaran dan indikator pembelajaran yang ingin dicapai.

Metode analisis data yang digunakan untuk mengetahui tingkat hasil belajar siswa adalah metode analisis deskriptif kuantitatif. Metode analisis deskriptif kuantitatif ini digunakan untuk menentukan tingkatan tinggi rendahnya hasil belajar IPA siswa. Pada akhir pembelajaran, siswa diberikan evaluasi untuk mengetahui tingkat keberhasilan siswa dalam pembelajaran. Hasil yang diperoleh siswa berupa skor yang telah ditetapkan dalam tata cara penskoran dan akan dikonversikan ke dalam Penilaian Acuan Patokan (PAP) skala lima. Tingkatan hasil belajar IPA siswa dapat ditentukan dengan membandingkan $\bar{P}$ atau rata-rata persen ke dalam PAP skala lima dengan kriteria pada Tabel 1. 
Tabel 1. Pedoman Konversi PAP Skala Lima tentang Tingkatan Hasil Belajar Siswa

\begin{tabular}{cc}
\hline Persentase & Kriteria \\
& Hasil Belajar \\
\hline $90-100$ & Sangat tinggi \\
$80-89$ & Tinggi \\
$65-79$ & Sedang \\
$55-64$ & Rendah \\
$0-54$ & Sangat rendah \\
\hline
\end{tabular}

Sumber: A.A Gede Agung (2005:97)

Keputusan untuk melanjutkan atau menghentikan penelitian pada siklus tertentu bergantung sepenuhnya pada hasil yang dicapai pada siklus terakhir. Bila hasil yang dicapai telah memenuhi kriteria keberhasilan yang telah diterapkan, maka penelitian dihentikan. Bila hasil yang dicapai belum sesuai dengan yang diharapkan, maka penelitian dilanjutkan ke siklus berikutnya. Penelitian ini dikatakan berhasil jika ketuntasan belajar siswa mencapai KKM minimal 70 dan ketuntasan klasikalnya minimal $85 \%$ atau berada pada kriteria tinggi.

\section{Hasil Dan Pembahasan}

Berdasarkan hasil evaluasi yang dilakukan terhadap siswa kelas IXB Semester ganjil SMP Negeri 2 Kubu tahun pelajaran 2016/2017 yang berjumlah 40 orang, diperoleh data hasil belajar siswa yang dapat dilihat pada Tabel 2 .

Tabel 2 Profil Hasil Belajar Siswa secara Klasikal

\begin{tabular}{cccccc}
\hline \multirow{2}{*}{ Variabel } & Tindakan & $\begin{array}{c}\text { Klasifikasi } \\
\text { Skala Lima }\end{array}$ & $\begin{array}{c}\text { Rata-rata } \\
\text { Nilai }\end{array}$ & Kategori & Ketuntasan belajar(\%) \\
\hline \multirow{3}{*}{ Hasil } & Pra Siklus & $55-64$ & 64,0 & Rendah & 37,5 \\
\cline { 2 - 6 } Belajar & Siklus I & $65-79$ & 66,8 & Sedang & 50,0 \\
\cline { 2 - 6 } & Siklus II & $80-89$ & 81,6 & Tinggi & 87,5 \\
\hline
\end{tabular}

Pada siklus I rata-rata hasil belajar siswa secara klasikal berada pada kategori rendah, yaitu $\bar{P}=$ 66,8, dan ketuntasan belajar siswa secara klasikal sebesar 50\%. Hal ini disebabkan guru belum mampu memanfaatkan media konkret dengan maksimal sehingga siswa kurang memperhatikan pelajaran dengan baik. Guru hendaknya mampu memanfaatkan media konkret tersebut dengan maksimal sehingga siswa mau memperhatikan pelajaran dengan baik. Media konkret yang digunakan selama proses pembelajaran yaitu pada pertemuan pertama menggunakan gambar alat reproduksi pada pria dan wanita,. Benda-benda tersebut digunakan sesuai dengan pokok bahasan yaitu sistem reproduksi dan penyakit yang berhubungan dengan sitem reproduksi manusia. Pada pertemuan kedua menggunakan gambar proses reproduksi pada manusia. Gambar-gambar tersebut digunakan sesuai dengan pokok bahasan sistem reproduksi dan penyakit yang berhubungan dengan sitem reproduksi manusia.

Rata-rata hasil belajar siswa secara klasikal pada siklus I sebesar 66,8 berada pada kategori rendah. Ketuntasan belajar siswa belum mencapai kriteria keberhasilan penelitian yang sudah ditargetkan. Hal ini menunjukkan perlu adanya perbaikan dalam proses pembelajaran. Pada siklus I terdapat 20 orang siswa yang berada di bawah KKM, hal ini disebabkan guru belum mampu menyampaikan tujuan pembelajaran dengan baik, sehingga keinginan siswa dalam belajar belum optimal. Guru harus mampu menyampaikan tujuan pembelajaran dengan baik agar siswa mengetahui tujuan pelajaran yang dipelajarinya. Guru terlalu cepat dalam menjelaskan materi sehingga siswa yang lambat menerima pelajaran menjadi tertinggal. Hal ini diperbaiki dengan cara memberikan materi secara lebih perlahan. Masalah lain yang timbul adalah siswa belum bisa meninggalkan kebiasaan dalam pembelajaran yang menggunakan metode ceramah, seperti bercanda di dalam kelas sehingga perhatiannya kurang terfokus pada pelajaran.

Pada siklus II terjadi peningkatan terhadap hasil belajar IPA siswa. Rata-rata hasil belajar siswa secara klasikal meningkat 14,8 poin, yaitu dari 66,8 menjadi 87,5 berada pada kategori tinggi. Ketuntasan belajar siswa meningkat sebesar $37.5 \%$, yaitu dari $50 \%$ menjadi $87.5 \%$. Terjadi peningkatan hasil belajar IPA karena pembelajaran dimulai dengan penyampaian tujuan pembelajaran, sehingga siswa dapat berkonsentrasi pada tujuan tersebut dan mengabaikan hal lain diluar tujuan pelajaran.

Media pembelajaran sudah dimanfaatkan dengan optimal, adapun media konkret yang digunakan pada pelaksanaan siklus II yaitu model mata manusia, model telinga manusia, gambar hidung manusia, 
gambar kulit manusia, gambar lidah manusia. Media tersebut digunakan sesuai dengan pokok bahasan sistem koordinasi dan alat indra pada manusia. Hal tersebut dapat menumbuhkan minat siswa dalam pembelajaran dan meningkatkan gairah belajar siswa. Siswa akan merasa tertarik, termotivasi untuk belajar. Penerapan model quantum teaching dimulai dengan menumbuhkan minat siswa untuk belajar, mengorganisasikan siswa untuk belajar, mengumpulkan informasi untuk menyelesaikan permasalahan, kemudian dilanjutkan dengan kegiatan menganalisis data atau informasi yang ditemukan untuk menemukan jawaban atau memecahkan suatu permasalahan.

Hal ini dikarenakan model quantum teaching memberikan sebuah pembelajaran yang meriah dan menyenangkan dengan berpegangan dengan asas "bawalah dunia mereka ke dunia kita, dan antarkan dunia kita ke dunia mereka". Model quantum teaching juga memiliki landasan dari prinsip yang kukuh seperti segalanya berbicara, segalanya mempunyai tujuan, pengalaman sebelum pemberian nama, mengakui setiap usaha, memberikan perayaan, dan tidak lepas pula dari strategi model quantum teaching yang mengambil istilah Tandur (DePorter, et al., 2011:39). Pembelajaran seperti ini hendaknya terus ditingkatkan untuk melatih keterampilan berpikir siswa, meningkatkan kecakapan pemecahan masalah, memotivasi siswa untuk belajar sehingga nantinya akan dapat meningkatkan hasil belajar siswa dan terciptanya SDM yang berkualitas.

Hasil yang diperoleh dalam penelitian ini didukung oleh penelitian sejenis yang dilakukan oleh Luh Putu Purnama Dewi, S.Pd. (2016), diketahui bahwa penerapan model pembelajaran kuantum dapat meningkatkan hasil belajar siswa. Selain itu temuan penelitian ini mendukung hasil penelitian yang telah dilakukan oleh oleh Gunarhadi (2010), Kusno dan Purwanto (2011), Suryani (2013), Acat dan Ay (2014) dan Suryani, et al (2014) yang sama-sama menghasilkan kesimpulan bahwa pembelajaran Quantum memberikan hasil belajar yang lebih baik daripada model pembelajaran eskpositori.

\section{Simpulan Dan Saran}

Berdasarkan hasil penelitian dan pembahasan, maka dapat diuraikan tiga simpulan yang merupakan jawaban terhadap rumusan masalah yang diajukan dalam penelitian ini, yaitu: penerapan model quantum teaching berbantuan media konkret pada mata pelajaran IPA dapat meningkatkan hasil belajar IPA siswa kelas IXB semester ganjil SMP Negeri 2 Kubu tahun pelajaran 2016/2017. Hal ini ditunjukkan dengan terjadinya peningkatan hasil belajar siswa pada setiap siklus.

Saran-saran yang dapat disampaikan dalam penelitian ini adalah sebagai berikut: (1) diharapkan kepada seluruh siswa khususnya di SMP Negeri 2 Kubu untuk memanfaatkan pengalaman belajar yang didapat setelah diterapkan model quantum teaching berbantuan media konkret dalam pelajaran IPA sehingga hasil belajar siswa dapat terus meningkat. (2) Sesuai dengan hasil penelitian tindakan kelas ini, disarankan kepada guru (pengajar) IPA agar dapat mempertimbangkan penerapan model quantum teaching berbantuan media konkret ini sebagai salah satu alternatif pilihan model pembelajaran dalam pembelajaran IPA guna meningkatkan motivasi belajar siswa yang secara tidak langsung dapat berimplikasi terhadap meningkatnya hasil belajar yang dicapai siswa. (3) Kepada Kepala SMP Negeri 2 Kubu diharapkan agar hasil penelitian ini dapat dijadikan dasar untuk membimbing dan mengarahkan staf pengajarnya dalam mengelola kegiatan pembelajaran sehingga pelaksanaan kegiatan pembelajaran menjadi lebih efektif. (4) Bagi para peneliti lain yang berminat mengadakan penelitian lebih lanjut dan sejenis tentang penerapan model quantum teaching berbantuan media konkret hendaknya lebih memperhatikan kendala-kendala yang dihadapi siswa dalam pembelajaran serta mengupayakan solusi pemecahan yang tepat agar penelitian yang dilaksanakan dapat mencapai hasil yang lebih maksimal sehingga dapat lebih memperkaya strategi pembelajaran.

\section{Daftar Rujukan}

Acat, M.B dan Ay, Y. 2014.An Investigation the Effect of Quantum Learning Approach on Primary School 7th Grade Students' Science Achievement, Retention and Attitude.Educational Research Association The International Journal of Research in Teacher Education, vol. 5, no. 2, hlm. 1123

Agung, A.A. Gede. 2005. Metodologi Penelitian Pendidikan. Singaraja: IKIP Negeri Singaraja.

Ali, M. 1982. Penelitian Kependidikan Prosedur dan Strategi. Bandung: Angkasa.

Arikunto, S. 1996. Prosedur Penelitian Suatu Pendekatan Praktek. Jakarta: Rineka Cipta.

Arsyad, A. 2002. Media pembelajaran. Jakarta: PT Rajagrafindo Persada. 
Dahar, R. W. 1988. Teori-teori Belajar. Jakarta: Pendidikan dan Kebudayaan.

Danial, Endang A. R., \& Dr. H. M.Pd. 2003. Penelitian tindakan kelas. Jakarta: Direktorat PLP, Dirjendikdasmen, Depdiknas.

DePorter, Bobbi \& Mike Hernacki. 2011. Quantum Learning Membiasakan Belajar Nyaman Dan Menyenangkan.

Depdiknas. 2002. Pendekatan Kontekstual (Contextual Teaching and Learning). Jakarta: Direktorat Pendidikan Dasar dan Menengah, Direktoral Pendidikan Lanjutan Pertama.

Dimyati \& Moedjiono. 1994. Strategi Belajar Mengajar. Jakarta: Depdikbud.

Gunarhadi. 2010. The Impact of Quantum Teaching Strategy on the Academic Achievement of Students in Inclusive Schools. Disertasi. Diakses dari http://etd.uum.edu.my/2383/2/1.Gun arhadi.pdf tanggal 24 Juni 2017.

Hasibuan \& Moedjino. 1996. Proses Belajar Mengajar. Bandung: Remadja Karya.

Hidayat, K., dkk.. 1987. Strategi Belajar Mengajar Bahasa Indonesia. Bandung: Bina Cipta.

Juniati, Ni Wayan dan I Wayan Widiana. (2017). Penerapan Model Pembelajaran Inkuiri Untuk Meningkatkan Hasil Belajar IPA. Jurnal Ilmiah Sekolah Dasar, Universitas Pendidikan Ganesha. Vol.1 (1) pp. 20-29.

Kasbolah, K. 1998. Penelitian Tindakan Kelas. Malang: Depdiknas.

Linto, Rendya Logina, Sri Elniati, dan Yusmet Rizal. 2012. Kemampuan Koneksi Matematis Dan Metode Pembelajaran Quantum Teaching Dengan Peta Pikiran . Jurnal Pendidikan Matematika, Vol. 1 No. 1 : Part 2 : Hal. 83-87.

Munandir. 2001. Ensiklopedia Pendidikan. Cetakan 1. Malang: UM Press.

Murizal , Angga, Yarman , Yerizon . 2012. Pemahaman Konsep Matematis Dan Model Pembelajaran Quantum Teaching . Jurnal Pendidikan Matematika Vol. 1 No. 1 Hal. 19-23

Muslikhah, Riana Isti , Siswandari dan Wiedy Murtini. 2016. Pengaruh Model Pembelajaran Quantum Teaching Berbantuan Flip Book Terhadap Hasil Belajar Ditinjau Dari Gaya Belajar Peserta Didik Pada Mata Pelajaran Pengantar Ekonomi Dan Bisnis. Jurnal Pendidikan Insan Mandiri Vol 1 No 1

Nurkancana, W. \& Sunartana. 1990. Evaluasi Pendidikan. Surabaya: Usaha Nasional.

Nuryati. 2015. Penerapan Model Pembelajaran Quantum Teaching Untuk Meningkatkan Hasil Belajar Ipa Siswa Kelas V Sd Negeri 24 Pekanbaru. Jurnal Primary Program Studi Pendidikan Guru Sekolah Dasar Fakultas Keguruan Dan Ilmu Pendidikan Universitas Riau, Volume. Volume 4 Nomor 2.

Purwanto, J dan Kusno. 2011. Effectiveness of Quantum Learning for Teaching Linear Program at the Muhammadiyah Senior High School of Purwokerto in Central Java, Indonesia (Versi Elektronik).EDUCARE:International Journal for Educational Studies, vol.4, no.1, hlm. 83-92. Diakses dari http://www.educareijes.com/educarefiles/File/07.kusno.j oko.ump.id.pdf tanggal 26 Mei 2014

Rohani, A. 1997. Media Intruksional Edukatif. Jakarta: PT Rineka Cipta.

Rusyan, A. T. 1993. Proses belajar mengajar yang efektif tingkat pendidikan dasar. Bandung: Bina Budhaya.

Sadiman, A. S. 2009. Media pendidikan. Jakarta: PT Rajagrafindo Persada. 
Sanjaya, W. 2008. Perencanaan Dan Desain Sistem Pembelajaran. Jakarta: PT Fajar Interpratam.

Suarjana, I Made, Dkk. 2007. Penerapan Pembelajaran Matematika Realistik Untuk Meningkatkan Prestasi Matematika Siswa Kelas III Sekolah Dasar Nomor 1 Paket Agung Singaraja. Skripsi. (Tidak Diterbitkan). Fakultas Ilmu Pendidikan Universitas Pendidikan Ganesha Singaraja.

Suartama, I K. 2008. Bahan Ajar Media Pembelajaran. Singaraja: UNDIKSHA.

Sudjana, Nana \& Admad, R. 1989. Teknologi Pengajaran. Bandung: Sinar Baru.

Sudjana. 1992. Metoda Statistik. Bandung: Tarsito.

Suryani, N. 2013. Improvement of Students' History Learning Competence through Quantum Learning Model at Senior High School in Karanganyar Regency, Solo, Central Java Province, Indonesia (Versi Elektronik). Journal of Education and Practice, vol.4, no.14, hlm. 55-63. Diakses darihttp://www.iiste.org/Journals/ind ex.php/JEP/article/download/6798/6 912 tanggal 27 Mei 2017.

Susiani, Ketut, Nyoman Dantes, I Nyoman Tika. 2013. Pengaruh Model Pembelajaran Quantum Terhadap Kecerdasan Sosio-Emosional Dan Prestasi Belajar Ipa Siswa Kelas V Sd Di Banyuning. e-Journal Program Pascasarjana Universitas Pendidikan Ganesha Jurusan Pendidikan Dasar Volume 3.

Syukur, Muhammad, Kartono, Sukmawati. 2014. Pengaruh Model Pembelajaran Quantum Teaching Terhadap Hasil Belajar Siswa SD. Jurnal Pendidikan dan Pembelajaran Volume 3 Nomor 9.

Undang-undang Republik Indonesia No 20 Tahun 2003 tentang Sistem Pendidikan Nasional.

Yanuarti, Ary, A. Sobandi. 2016. Upaya Meningkatkan Hasil Belajar Siswa Melalui Penerapan Model Pembelajaran Quantum Teaching . Jurnal pendidikan manajemen perkantoran Volume 1, nomor 1 halaman $11-18$.

Wiriatmadja, Rochiati, Prof.Dr. (2005). Metode Penelitian Tindakan Kelas. Bandung: PPS sUPI dan Remaja Rosdakarya. 